\title{
Role of Decision Making Models in District Scenario Planning
}

\author{
Satyajit Rath \\ CSIR-Institute of Minerals \& \\ Materials Technology, \\ Bhubaneswar, India
}

\author{
Sateesh K Pradhan \\ Dept. of Computer Science and \\ Applications, Utkal University, \\ Bhubaneswar, India
}

\author{
V N Shukla \\ Center for Development of \\ Advance Computing, \\ Noida, India
}

\begin{abstract}
While a country is surging ahead from a developing country to the status of a developed nation, the term "Development" has a connotation, both in terms of macro-level or micro-level development. When referred at the country level it becomes macro-level development, while at districts, it becomes microlevel development. At the sub-state level, "District" is the basic unit for all administrative purpose and also consistent with the decentralized planning process prevailing at the grass-root. However, the planning and development at district level can be further subdivided into urban planning and rural planning. Urban planning basically focuses on urban areas for its planned development with proper land use. These activities are generally taken cared by respective Urban Development Authorities. Planning at rural level can further be zeroed down to village / habitation. As part of the Planning objectives, Rural Planning needs to reflect growth and social justice, as growth in the rural sector has been identified as the key to social and economic development.
\end{abstract}

Development involves making decisions and informed choices amongst alternative possible development paths. Therefore, it is important that these decisions are made using the best information, methods and tools available in an effective manner. The information to be considered for planning may be of sectoral or non-sectoral in nature. Today's scenario is focused on planning and each department plans for assigned limited sectoral development. However development of each sector is dependent on each other. For this purpose planners take decisions on the questions like Where, Why, How etc. When we talk about decisions, there are various decision models available to choose from depending upon the requirement. This paper deliberates the aspects of sectoral planning and the role of decision models in this planning process and its effectiveness with respect to planning.

\section{General Terms}

Multiple Criteria Decision Analysis (MCDA), Analytic Hierarchy Process, Goal Programming Data Envelopment Analysis.

\section{Keywords}

District Planning, Multiple Criteria Decision Analysis (MCDA), Analytic Hierarchy Process, Primary Education, Primary Health Centre

\section{INTRODUCTION}

Planning is the base of any work to be accomplished in a meaningful manner. The work could be some construction work, application software development work, maintenance work etc. Each of these work do require a planning before actually starting the execution. As an example, to select appropriate remedial measures for polluted areas, land use planning, and other planning processes often involves several additional criteria like the distribution of costs with respect to benefits, environmental impacts for different populations, safety, ecological risk, or human values. When it comes to developmental activity for a district, it's the national revenue get utilized for the benefit of the people. Without proper planning and execution the objectives do not fulfilled as it should be. In this context, various programs/ schemes were being released for implementation and practices.

Development planning is a process of decision making about rational choices through which we try to achieve our objectives with the limited resource available. Since last decade national policies from per capita income approach has shifted to planning for human well-being. The broader dimensions of well-being are individual attainments in areas of education and knowledge; health and longevity; as well as in the quality of overall social and physical environment of people.

For policy making \& planning purpose, district is the most important administrative unit. Each district administration plans, implements and monitors the development programs which are aided by central, state and international agencies. Better coordination can be achieved through planning on a common dataset at district level.

Planning at the district level focuses on further smaller units, the Block and / or Panchayat narrowing down to village and Hamlets. The planners / decision makers enlist and ascertain facilities available at village, block and district levels and make plans for the maximum/optimal use of natural and other resources

To achieve these objectives, planners and decision makers get jumbled between questions like what to develop and where to develop. Most real-world decision problems involve multiple criteria that are often in conflict in general and it is sometimes necessary to analyze using multiple criteria decision analysis (MCDA).

This paper is intend to indicate the developmental aspects at district level and proposes the use of Multiple Criteria Decision Analysis (MCDA) for planning of facilities with respect to Health \& Education at district level.

\section{DISTRICT PLANNING}

In due course of time, as the population grows, it became inevitable to make the process of planning and development decentralized. The 73rd and 74th amendments to constitution led to the setting of decentralized democratic local selfgovernment. Most of the state governments initiated experiments in decentralized planning with different 
approaches. As per The constitutional provision of decentralization planning shows the need of setting up of a District Planning Committee (DPC). District authorities plan, implement and coordinate the development programs aided by Central Government, State Government, District plan and External funding agencies. Some of the important programs are

\section{Central Schemes}

- Pradhan Mantri Gramin Sadak Yojana (PMGSY)

- Rajiv Gandhi Drinking Water Mission

- Drought Prone Areas Program.

State Schemes

- Ambedkar Village, UP Government

- Gokul Gram Yojana, Gujarat Government

- Janamabhoomi Program, Andhra Pradesh Government

Externally funded programs

- $\quad$ District Primary Education Project (DPEP), World Bank

- State Health System Project, World bank

- $\quad$ Rural Infrastructure Development Fund, NABARD

At District

- District Plan

- $\quad$ Priorities of MP/MLA for Local Area Development

The guide lines and implementation criteria may be different for various programs, but broadly the objectives are to improve or provide basic facilities in Education, Health, Connectivity, Power, Irrigation, drinking water etc. for human well being.

During the study, it is understood that desired coordination between various agencies and schemes are lacking. Sometime this lacking in co-ordination results in duplication of the efforts for achieving the same development objective. The other important issue is that some time planning of these programs are done at random due to non-availability of data or inadequate analysis of data.

Better coordination can be achieved if all programs are planned on common centralized databases created at the base administrative level. The District Planning Committee (DPC) will be the nodal agency for preparation of district plans and respective departments to implement the plans. This committee consists of representatives from elected members, Districts Authorities and Sectoral/ Departmental Officers.

\subsection{Some of the responsibilities assigned of the District Planning Committee are:}

- To enlist and ascertain facilities available at village, block and district levels

- To make plans for the maximum/optimal use of natural and other resources

- To consolidate annual and five year plans of the district in accordance with larger national and state priorities and objectives

- To prepare employment schemes for the district
- To assist in financial planning for the district

- To review, evaluate and provide feedback on schemes being implemented in the district

- To allocate the cost of implementation for sectoral and sub-sectoral projects within the overall structure of the district development scheme

Structured Databases will help the DPC in quickly understanding the ground situation and making better decisions.

\subsection{Current Practice in District Planning}

In every district Economic and Statistical wing of the State planning departments compiles district information of various parameters and publish the District Statistical Handbook. This practice is almost common across the states. But often the data maintained by Statistical departments doesn't match with the decision-making criteria of District Magistrate / District Planning committee. They rely on the data maintained by departments. The inbuilt hierarchical structure of government organizations causes inordinate delay in supplying the data to the top decision makers of the organizations due to following reasons:

- Timely, non availability of data leads to delay in implementation of planning targets

- Data is not in proper format for decision-making

- Data source is not known

- Data are sometimes old and not updated periodically

Most of time the departments supply the aggregated data to decision makers, so decision makers may not get desired insights of development status at gross roots.

This leads to delay in implementing planning objectives of the government. The importance of current data and information cannot be over-emphasized for planning to be effective and efficient. Timely data availability and its management is crucial for the vision, performance, planning and contributes directly to the structured development of any area.

A number of plan schemes are in operation with similar objectives targeting the same population. It is also obvious that in order to synthesize the works of different agencies and eliminate duplication of works among the agencies, the concept of Central Database arises. A proper database can augment more insight with number of decision alternatives.

\subsection{Current Practice in Data Analysis}

It is being learnt that district officials spend much time in collecting data, and little time devoted for analysis. A numbers of programs run at different level and with the absence of advance record keeping measures, monitoring of the effectiveness of the programs are extremely difficult. On the other hand, investment made across the social sector should be rationally optimized at the fullest possible way.

The objective of development is human well-being and intersectoral linkage will be extremely important in attaining the overall development. For example while sanctioning the rural roads connectivity, the existing public health centers, schools, market centers, backward/tribal areas, and areas of economic importance should also be taken into consideration.

Decision makers also require information like access to health, education and road facilities by the people and where 
the potential beneficiaries live and what is type of their distribution etc. Maps are the easiest and better way to represent this type of data than normal tables. Along with structured databases there is a greater need for analysis of data as per objectives of various programs.

\section{DATA FOR DISTRICT PLANNING}

Under a normal practice, at district administration, a longer duration is spent in collecting the information, there by leaving very little time for analysis.

Now the concept of development is human well-being and inter sectoral linkage will be extremely important in attaining the overall development. For example while sanctioning the rural roads connectivity, the existing public health centers, schools, market centers, backward/tribal areas, and areas of economic importance should also be taken into consideration.

Decision makers also require information like access to health, education and road facilities by the people and where the potential beneficiaries live and what is type of their distribution etc. Maps are the easiest and better way to represent this type of data than normal tables. Along with structured databases there is a greater need for analysis of data as per objectives of various programs.

Besides the base map of the district indicating administrative boundaries the following attributes are required for the corresponding sectors.

\section{Education}

- All Primary and Middle School locations on map.

- School wise information:

- Category wise student's enrollment.

Facilities available in each school.

Number of Teachers working.

- $\quad$ Literacy rates

- Village wise out of school and school going children.

Health

- Community Health Centre (CHC), Primary Health Centre (PHC), and Sub Centre locations on map.

- Villages covered by each sub centres

- Important Disease reported at PHC levels

- $\quad \mathrm{PHC}$ wise available infrastructure details

- $\quad$ PHC wise staff details

- All the data required for reporting at Sub Centre wise to Centre and State level

Road

- Existing Road Network:

$\begin{array}{ll}\circ & \text { National Highways. } \\ \circ & \text { State Highways. } \\ \circ & \text { Major District Road. } \\ \circ & \text { Other District Roads. } \\ \circ & \text { Village Roads. }\end{array}$

- Habitation / Villages connected with all weather roads.

- Habitation / Villages not connected with all weather roads.

- For habitation / Villages roads are under construction.

- Scheme wise roads are under construction.

- Roads proposed to connect the Habitation / Villages.

Power

- $\quad$ Electrified / un-electrified villages details.

- Details of $66 \mathrm{kV}, 33 \mathrm{kV}, 11 \mathrm{kV}$ and LT network.
- Locations of Sub stations

- Locations of Transformers.

\section{LITERATURE STUDY OF METHODOLOGIES FOR AIDING BETTER DECISIONS}

\subsection{Multi-Criteria Decision Analysis}

Multi-Criteria Decision Analysis (MCDA), or Multi Criteria Decision Making (MCDM), is a discipline aimed at supporting decision makers who are faced with making numerous and conflicting evaluations. MCDA aims at highlighting these conflicts and deriving a way to come to a compromise in a transparent process. Umm and Sohail explores a critical survey on Multi-Criteria Decision Making Approaches [32] and revealed that the market is in need of a hybrid decision making system, which can overcome complex problems by using modern DSS technologies. The authors in [13] have used MCDA by integrating with Geographical Information System (GIS) to analyze the influences of natural and ecological factors on the suitability of residential land and got the best area considered for residential land. The concept of MCDA has been used in numerous fields. MCDA has been used for decision making in a systems-of-systems application for dynamic behavior assignment in sensor network to increase the lifetime of the network [23]. A similar kind of work has been done in [20].The work [20] demonstrates the viability of applying Scenario Planning with MCDA in operational and strategic environments. It is remarked that any MCDA technique could be used to assess the strategic options in scenario planning. GIS is integrated with MCDA to provide more flexible and more accurate decisions to the decision makers in order to evaluate the effective factors for flood vulnerable areas in Hadejia-Jama'are River Basin, Nigeria [27]. A review of the available literature and provides recommendations for applying MCDA techniques in environmental projects has explored in [8] and a generalized framework for decision analysis is proposed to highlight the fundamental ingredients for more structured and tractable environmental decision making. The extensive growth in the amount and diversity of information required for decision making has exceeded the capacity of common, unstructured decision models. The effort has directed at integrating hybrid tools with existing approaches, including the use of risk and cost-benefit analysis, will lead to more effective, efficient, and credible decision making.

\subsection{Analytic Hierarchy Process (AHP)}

The Analytic Hierarchy Process (AHP) is a structured technique for helping people deal with complex decisions. Rather than prescribing a "correct" decision, the AHP helps people to determine one. Based on mathematics and human psychology, it was developed by Thomas L. Saaty in the 1970s and has been extensively studied and refined since then. The AHP provides a comprehensive and rational framework for structuring a problem, for representing and quantifying its elements, for relating those elements to overall goals, and for evaluating alternative solutions. It is being used by many numbers of researchers, scientist all over the world in a wide variety of decision situations, in fields such as government, business, industry, healthcare, and education. For a long time, from early 1970 s to till date people are working on this technique for managing their information and making decisions for the unstructured problem. Bertolini and et al has been applied AHP to determine the best percentage of discount to be applied in the proposals of a company which 
decorates and/or carries out maintenance of parks and public gardens with a public work contract [18]. Luis and et al has reviewed AHP with other two methodologies for identifying, classifying and evaluating CSFs in IT projects and conclude that the AHP methodology has certain advantages compared to methodologies using qualitative analysis based merely on the experts' opinions of the absolute priorities of each CSF as it allows a measure of the consistency of the results [17]. Henny and et al presents a decision-making model using AHP that provides support to managers confronted with the choice of whether to maintain production internally, or at least parts of it, or to outsource [10]. They claims, this decision support model will make companies facing the Make or Buy question consider the financial as well as the non-financial factors more comprehensively. Fariborz has presented a new analytical method of facility location decision which takes into account both external (customer wants, status of competition, and characteristics of location) and internal (critical internal processes) criteria that sustain competitive advantage [7]. Kawang and Youn have purposed an approach for identifying relative importance of factors to improve passenger security checks at airports [16]. Chen and Liu purposed a new methodology for evaluation and classification of rock mass quality that can be applied to rock tunneling [3]. They argue that the proposed method can be successfully applied to determine the ratings of rock mass quality for the cases of tunnel engineering. Carlos and et al says that AHP is a methodology that deals with problems in an easy, flexible and economical manner. Therefore it is a potentially useful tool for the practical resolution of complex problems, often an object of Ecological Economics. They have used this methodology for a systemic comparative assessment of the multifunctional performance of alternative olive systems in Spain [2]. Theresa and et al used the AHP method for choosing the preference for their problem and they demonstrate that the AHP offers potential for actual application as a public participation tool [30]. Rhonda and et al has used AHP for group decision making by aggregating individual judgments or individual priorities [26]. In this study they determine the threshold values for various dimensions of the aggregated comparison matrix. Ezatollah explores the use of analytic hierarchy process (AHP) for selecting an appropriate irrigation method [5]. An AHP based modeling framework for the prioritization of energy conservation policy instruments has been presented by Kablan [19]. He suggests that AHP may be used to support management to structure in the form of a hierarchy of goal, criteria, and alternatives. Younghwa and Kenneth explores a study to investigates the website quality factors and their relative importance in selecting the most preferred website, and the relationship between website preference and financial performance with online customers and managers/designers of e-business companies by applying analytic hierarchy process method. Their study suggests that the AHP could also be applied to resolving various multi-criteria decision making problems in e-business areas [34]. Xiong and et al developed a method to evaluate eco-environment quality in Hunan Province, China [33]. They have combined the AHP with GIS to provide an improvement method for synthetic evaluation of eco-environment quality. The result showed by this method is satisfactory. A decision models and decision-support systems has been developed by Oded and et al for designing and performing cost-benefit analysis of Health Information Networks [22]. They claims that this model can also be used for prioritizing access and use in the settings where the use of the network may require substantial commitment of financial and human resources. A decision support technique has been presented by Chedid and et al develop a decision support technique which can help decision makers optimally design grid-linked renewable energy systems [24]. In this technique they have used AHP to quantify the various divergences of opinions, practices and events that lead to confusion and uncertainties in planning hybrid solar-wind power system. A multiple-criteria decision-making approach for the evaluation of Retail Location has been presented by Sebnemburnaz and Ilker [28]. A system has been developed for evaluating the outcomes of multidisciplinary R\&D projects using the AHP model [14]. They have modified the AHP method to suit the needs of this evaluation by a fuzzy approach to improve the effectiveness of the measurement on unstructured variables. An empirical methodology to determine cardinal criteria weights on the basis of only individual ordinal ranking of these criteria has been presented by Heshamk and Saliho [11]. They also have purposed a model for each individual decision maker in which the weight of each criterion is a function of both its rank and the total number of criteria. Massod purposes a methodology using analytic hierarchy process and multi-objective goal-programming which can help facility planning authorities to formulate viable location strategies in the volatile and complex global decision environment [21]. He claims that the combined AHP-GP method offers a systematic approach to the location-allocation decision problem.

\subsection{Goal Programming (GP)}

GP is another aspect of multi-criteria decision analysis. It can be thought of as an extension or generalization of linear programming to handle multiple, normally conflicting objective measures. Each of these measures is given a goal or target value to be achieved. Unwanted deviations from this set of target values are then minimized in an achievement function. This can be a vector or a weighted sum dependent on the goal programming variant used. T Gomez et al [29] presents a linear fractional goal programming model to a timber harvest scheduling problem in order to obtain a balanced age class distribution of a forest plantation in Cuba. A similar kind of work has been carried out in [4]. They have used a fuzzy goal programming approach for rural development planning. They have used the model to assess employment opportunity in rural area by keeping in mind the operational cost and economic activities of the rural farmers. John and Michael [12] have developed a model which allow decision makers to set case mix and case costs in such a way that the institution is able to break even, while preserving physician income and minimizing disturbance to practice. Animesh and Bijay explores how fuzzy goal programming technique can be efficiently used for modeling and solving land-use planning problems in agricultural systems for optimal production of several seasonal crops in a planning year [1]. In [9], the author has developed a system using goal programming with personal computer to support decision makers working out semi-large size multi-criterion programming. Gabiane et al [6] has used Goal programming in a land allocation planning problem.

\subsection{Data Envelopment Analysis (DEA)}

DEA is a nonparametric method in operations research and economics for the estimation of production frontiers. It is used to empirically measure productive efficiency of decision making units. There are also parametric approaches which are used for the estimation of production frontiers. Rafael et al purposes a methodology to serve as a guiding mechanism for the allocation and management of university financial resources taking efficiency as its objective [25]. The model 
they have provided is based on the use of two quantitative techniques i.e. DEA and MCDM. For determining the most efficient number of operators and the efficient measurement of labor assignment in cellular manufacturing system (CMS) Tijen and Da [31] purposed a decision making approach based on data envelopment analysis (DEA). The purposed model has been applied to an experimental data set consisting of 48 simulation scenarios. Kemal and Ilhan have used DEA for the performance comparison of Turkish power plants which include public versus private sector plants, and natural gas versus coal versus oil fired plants [15].

\section{DISTRICT PLANNING WITH DECISION MODEL}

The significant feature of this system is its support to decision makers in planning the resource utilization. Normally these decisions are taken based on parameter only specific to that utility. Instead of using single parameter for planning, it was found that multi-criteria based planning would be a better effective option. With this thought, the Analytical Hierarchy Process (AHP) Model has been chosen to be introduced.

\subsection{Analytical Hierarchy Process (AHP)}

Decision making involves, choosing an option that will benefit more than any other options. "More" in this sentence is a mathematical concept: In this case, computers can help to find the option that leads to the highest, numerical score. The Analytical Hierarchy Process is the technique to do this.

Elements of Decision Making via AHP

- Goal

- $\quad$ Objectives

- $\quad$ Sub-objectives (Criteria)

- Alternatives (Course of Action)

The methodology is known as Analytical Hierarchy Process (AHP), which is a "decision hierarchy, containing a mission statement, objectives or criteria, and alternatives of choice" and "evaluated by deriving ration scale priorities from pair wise judgments."

AHP is a mathematical theory for measurement and decision making that was developed by Professor Saaty during 1970's. AHP allows decision makers to model a complex problem in a hierarchical structure showing the relationships of goal, objectives (criteria), sub-objectives, and alternatives.

\subsection{Structuring a Hierarchy}

Generically, AHP is one of the techniques of Multi-Criteria Decision Making (MCMD). The most important and creative part of decision making that has a significant effect on the outcome is how the problem is conceived and then modeled.

In the AHP, a problem is modeled as a Hierarchy. This is followed by a process of prioritization. Prioritization involves eliciting judgments in response to questions about the dominance of one element over another when compared with respect to a specific criterion.

Relative evaluation is the kernel of the methodology. Indeed, ratio scales, proportionality and normalized ratio scales are central for comparison needed to determine and synthesize priorities, whether in AHP or any multi-criteria method.

AHP has appeal to managers and decision makers at all levels of decision making. It enables one to include both the strength of feeling needed to express judgment and the logic and understanding relating to the issues involved in the decision. It combines the multiplicity of judgments into a systematic framework to obtain the best outcome or mix of actions. Finally, and more significantly, these outcomes derived in an agreeable and transparent way are in harmony with our intuition and understanding and not forced by technical manipulations.

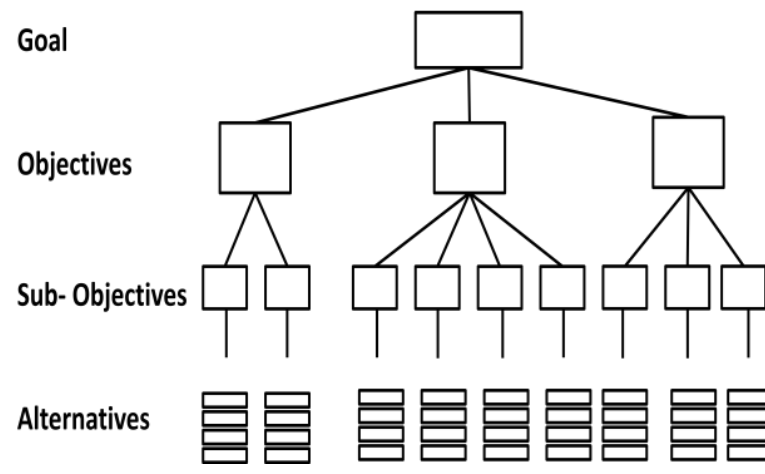

Fig 1. Decision Hierarchy

\section{CONCLUSION}

Policies are made to provide a SMART (Simple, Moral, Accountable, Responsive \& Transparent) government to citizens. To have a developed nation, the policies shall be planned and implemented in a manner so to have optimum benefits. In this direction the GIS based Decision Support System does not formulate any decision; rather it helps the decision makers to take an optimum and appropriate decision. The approach indicated in the system can be considered as an initiation with the AHP model. This has been aimed to improve the planning process within the district. The same approach can be applicable to planning activities.

\section{REFERENCES}

[1] Animesh Biswas, Bijay Baran Pal, "Application of fuzzy goal programming technique to land use planning in agricultural system" Elsevier, Omega 33 (2005) 391 398

[2] Carlos Parra-Lópeza, Javier Calatrava-Requenaa, Tomás de-Haro-Giménezb, A systemic comparative assessment of the multifunctional performance of alternative olive systems in Spain within an AHP-extended framework, Ecological Economics 64(2008) 820 - 834.

[3] Chao-Shi Chen, Ya-Ching Liu, A methodology for evaluation and classification of rock mass quality on tunnel engineering, Tunnelling and Underground Space Technology 22 (2007) 377-387.

[4] Dinesh K. Sharma a,*, Debasis Ghosh b, Julius A. Alade, "A fuzzy goal programming approach for regional rural development planning" Elsevier, Applied Mathematics and Computation 176 (2006) 141-149

[5] Ezatollah Karami, Appropriateness of farmers_adoption of irrigation methods: The application of the AHP model, Agricultural Systems 87 (2006) 101-119

[6] Fabiane de Oliveira, Neida Maria Patias Volpi,Carlos Roberto Sanquetta, "Goal programming in a planning problem", Elsevier, Applied Mathematics and Computation 140 (2003) 165-178 
[7] FariborzY. Partovi,An analytic model for locating facilities strategically, Omega, The Int. Journal Of Management Science, 34 (2006) 41 - 55

[8] Gregory A. Kiker, Todd S. Bridges, Arun Varghese, Thomas P. Seager, and Igor Linkovjj, "Application of Multicriteria Decision Analysis in Environmental Decision Making", Integrated Environmental Assessment and Management - Volume 1, Number 2 - pp. 95-108

[9] Guoqiang Sun, Tetsuo Ui, Hidetoshi Nakayasu, "Development of a practical goal programming system for solving semi-large size multi-criterion planning problems", Elsevier, Int. J. Production Economics 39 (1995) 227-242

[10] Henny van de Water_, Heleen P. van Peet, A decision support model based on the Analytic Hierarchy Process for the Make or Buy decision in manufacturing, Journal of Purchasing \& Supply Management 12 (2006) 258271.

[11] Heshamk. Alfares and Saliho. Duffuaa, Assigning CardinalWeights inMulti-Criteria Decision Making Based on Ordinal Ranking, Journal Of Multi-Criteria Decision Analysis, 2008

[12] John T. Blake, Michael W. Carter, "A goal programming approach to strategic resource allocation in acute care hospitals" ELSEVIER, European Journal of Operational Research 140 (2002) 541-561

[13] Kaili Dou, Qingming Zhan, Shiguo Li, "Selection of Residential Land based on Integration of MCDA and Gravity Model”, 2009 IEEE

[14] Kangmao Wang, Clement K. Wang, and Chun Hu, Analytic Hierarchy Process With Fuzzy Scoring in Evaluating Multidisciplinary R\&D Projects in China, IEEE Transactions on Engineering Management, vol. 52, no. 1 , february 2005

[15] Kemal Sarıca, Ilhan Or, "Efficiency assessment of Turkish power plants using data envelopment analysis", Elsevier, Energy 32 (2007) 1484-1499

[16] Kwang Eui Yooa, Youn Chul Choib, Analytic hierarchy process approach for identifying relative importance of factors to improve passenger security checks at airports, Journal of Air Transport Management 12 (2006) 135142 .

[17] Luis Rodriguez-Repisoa, Rossitza Setchib,_, Jose L. Salmeronc, Modelling IT projects success: Emerging methodologies reviewed, Technovation 27 (2007) 582594

[18] M. Bertolini, M. Braglia, G. Carmignani b, Application of the AHP methodology in making a proposal for a public work contract, International Journal of Project Management 24 (2006) 422-430.

[19] M.M. Kablan, Decision support for energy conservation promotion: an analytic hierarchy process approach, Energy Policy 32 (2004) 1151-1158

[20] Marcelo Zawadzki and Danielle Araujo, "Applying the Scenario Planning Approach to support Multicriterial Strategic Assessment" 2011 IEEE International MultiDisciplinary Conference on Cognitive Methods in Situation Awareness and Decision Support (CogSIMA), Miami Beach, FL

[21] Masood A. Badri, Combining the analytic hierarchy process and goal programming for global facility location-allocation problem, Int. J. Production Economics 62 (1999) 237\}248

[22] Oded Berman, Fatemeh "Mariam" Zahedi, and Kim R. Pemble, A Decision Model and Support System for the Optimal Design of Health Information Networks, IEEE Transactions On Systems, Man, And Cybernetics-Part C: Applications And Reviews, Vol. 31, No. 2, May 2001

[23] Prasanna Sirdhar, Asad M. Madni, Mo Jamshidi, "MULTI-CRITERIA DECISION MAKING AND BEHAVIOR ASSIGNMENT IN SENSOR NETWORKS” 2007 1st Annual IEEE Systems Conference, Waikiki Beach, Honolulu, Hawaii, USA April 9-12, 2007

[24] R. Chedid, Member IEEE \& H. Akiki, Saifur Rahman, Senior Member IEEE, A Decision Support Technique For The Design Of Hybrid Solar-Wind Power Systems, IEEE Transactions on Energy Conversion, Vol. 13, No. 1, March 1998

[25] Rafael Caballero, Teodoro Galache, Trinidad Go'mez, Julian Molina, Angel Torrico, "Budgetary allocations and efficiency in the human resources policy of a university following multiple criteria”, Elsevier, Economics of Education Review 23 (2004) 67-74

[26] Rhonda Aull-Hyde, Sevgi Erdogan b, Joshua M. Duke, An experiment on the consistency of aggregated comparison matrices in AHP, European Journal of Operational Research 171 (2006) 290-295

[27] Sani Yahaya, Noordin Ahmad, Ranya Fadlalla Abdalla, "Multicriteria Analysis for Flood Vulnerable Areas in Hadejia-Jama'are River Basin, Nigeria”, European Journal of Scientific Research, ISSN 1450-216X Vol.42 No.1 (2010), pp.71-83

[28] Sebnemburnaz and Y. Ilker Topcu, A Multiple-Criteria Decision-making Approach for the Evaluation of Retail Location, Journal Of Multi-Criteria Decision Analysis, 67-76, 2006

[29] T. Go'mez, M. Herna'ndez, M.A. Leo'n, R. Caballero, "A forest planning problem solved via a linear fractional goal programming model" Elsevier, Forest Ecology and Management 227 (2006) 79-88

[30] Theresa Mau-Crimminsa, J.E. de Steiguera, Donald Dennisb, AHP as a means for improving public participation: a pre-post experiment with university students, Forest Policy and Economics 7 (2005) 501514.

[31] Tijen Ertay, Da Ruan, "Data envelopment analysis based decision model for optimal operator allocation in CMS" European Journal of Operational Research 164 (2005) 800-810

[32] Umm-e-Habiba and Sohail Asghar, A Survey on MultiCriteria Decision Making Approaches, 2009 International Conference on Emerging Technologies, 2009 IEEE

[33] Xiong Yinga,b, Zeng Guang-Minga, Chen Gui-Qiua, Tang Lina, Wang Ke-Linc, Huang Dao-Youc, Combining AHP with GIS in synthetic evaluation of ecoenvironment quality - A case study of Hunan Province, China, ecological modelling 209 ( 2007 ) 97-109

[34] Younghwa Lee, Kenneth A. Kozar, Investigating the Effect of Website Quality on e-Business Success: An analytic Hierarchy Process Approach, Decision Support Systems 42 (2006) 1383-1401 